\title{
Mechanochemical Synthesis \\ of Fine Carbide-Containing Catalysts \\ for Hydroconversion of Heavy Oil Residues
}

\author{
Anastasia V. Vasilevich, \\ Olga N. Baklanova, Dmitrij V. Golinskij, \\ Mihail V. Trenihin and Aleksandr V. Lavrenov* \\ Institute of Hydrocarbons Processing SB RAS \\ 54 Neftezavodskaya Str., Omsk, 644040, Russia
}

Received 12.07.2018, received in revised form 12.11.2018, accepted 29.11.2018

Fine molybdenum-carbide catalytic systems were obtained by the method of mechanical activation in an inert atmosphere. The composition and morphology were investigated, the catalytic behavior of molybdenum-carbide systems was estimated in the hydrotreatment process of vacuum residue. In the presence of a molybdenum-carbide catalyst, a decrease in the coke yield by more than three times is observed compared to the coke content obtained with the same temperature-time parameters of the process without a catalyst.

Keywords: mechanical activation, catalyst, molybdenum carbide, hydroconversion.

Citation: Vasilevich A.V., Baklanova O.N., Golinskij D.V., Trenihin M.V., Lavrenov A.V. Mechanochemical synthesis of fine carbide-containing catalysts for hydroconversion of heavy oil residues, J. Sib. Fed. Univ. Chem., 2018, 11(4), 564-574. DOI: $10.17516 / 1998-2836-0100$.

(C) Siberian Federal University. All rights reserved

* Corresponding author E-mail address: vasilevich.ihcp@mail.ru 


\title{
Механохимический синтез
}

\section{высокодисперсных карбидсодержащих катализаторов для гидроконверсии тяжелых нефтяных остатков}

\author{
А.В. Василевич, О.Н. Бакланова, \\ Д.В. Голинский, М.В. Тренихин, А.В. Лавренов \\ Институт проблем переработки углеводородов СО РАН \\ Россия, 644040, Омск, ул. Нефтезаводская, 54
}

Высокодисперсные молибден-карбидные каталитические системы были получены методом механической активации в инертной среде. Исследован состав, морфология и проведена оценка каталитического поведения молибден-карбидных систем в slurry-прочессе гидропереработки гудрона, установлено, что в присутствии молибден-карбидного катализатора наблюдается снижение выхода кокса более чем в три раза по сравнению с содержанием кокса, полученного при тех же температурно-временных параметрах процесса без катализатора.

Ключевые слова: механическая активачия, катализатор, карбид молибдена, гидроконверсия.

\section{Введение}

Одной из важнейших задач современной нефтепереработки является повышение эффективности использования нефтяного сырья; в связи с этим тяжелая нефть и вакуумный остаток рассматриваются как альтернативный источник транспортных топлив и продуктов нефтехимии, которые смогут удовлетворить запросы современной цивилизации.

Процессы гидропереработки - основные процессы для превращения тяжелых нефтяных фракций с высоким содержанием углерода до продуктов с низкими температурами кипения. Тяжелые остатки представляют собой сложную дисперсную систему, при конверсии которой в зоне реакции образуются термически неустойчивые высокомолекулярные фрагменты деструкции смол и асфальтенов, которые способствуют образованию кокса на внешней поверхности катализатора и его дезактивации.

Переход на переработку высокосернистого нефтяного сырья, вовлечение дистиллятов вторичного происхождения увеличивают требования к уровню активности катализаторов гидропроцессов, особенно в части эффективного удаления, наряду с сернистыми, азот- и кислородсодержащими соединениями, смолистых веществ и снижение содержания полициклических ароматических углеводородов.

Применение высокодисперсных катализаторов и организация суспензионного slurryпроцесса позволяют достигать высокой конверсии наряду с низким выходом кокса и газа. При разработке подобных процессов для достижения существенных преимуществ необходимо создание новых каталитических систем.

Перспективное решение задачи переработки тяжелых остатков - использование в качестве катализатора высокодисперсных карбидов переходных металлов, а именно карбида молибде-

$$
-565-
$$


на. Карбиды молибдена широко исследуются в последние годы из-за своей уникальной электронной структуры [1]. Известно, что карбиды молибдена являются соединениями, в которых электронные характеристики подобны электронным характеристикам благородных металлов, принадлежащим группам IX и X [2-4]. Катализаторы на основе карбида молибдена проявляют высокую каталитическую активность и селективность в процессах гидрирования [5-7], гидродесульфуризации [8], гидродеазотирования [9], гидродеоксигенации [10], гидродеароматизации [11], реформинга метана [12, 13], Фишера-Тропша [14], ароматизации [15], изомеризации [16], а также в качестве электрокатализаторов [17, 18].

Важные преимущества катализаторов на основе карбида молибдена - высокая стабильность в присутствии каталитических ядов - $\mathrm{CO}$ и $\mathrm{S}$, низкая стоимость и широкая доступность по сравнению с благородными металлами $[19,20]$.

Катализаторы на основе карбида молибдена устойчивы к истиранию и спеканию в ходе технологического процесса, проявляют высокую термическую стабильность в отсутствие окислительной среды [21].

В настоящей работе был предложен синтез молибден-карбидных каталитических систем методом механической активации (МА). Проведена оценка каталитического поведения молибден-карбидных систем в slurry-процессе гидропереработки гудрона.

\section{Экспериментальная часть}

В работе были приготовлены две серии образцов: молибден-карбидная каталитическая система (МC) и молибден-карбидная каталитическая система с добавкой никеля (MCN). В качестве исходных соединений были выбраны гептамолибдат аммония $\left(\mathrm{NH}_{4}\right)_{6} \mathrm{Mo}_{7} \mathrm{O}_{24} \cdot 4 \mathrm{H}_{2} \mathrm{O}$ «Sigma-Aldrich» и нитрат никеля $\mathrm{Ni}\left(\mathrm{NO}_{3}\right)_{2} \cdot 6 \mathrm{H}_{2} \mathrm{O}$, в роли карбидизирующего агента использовали технический углерод марки П145, характеристики которого приведены в табл. 1. Механическую активацию проводили в водоохлаждаемой планетарной мельнице АГО-2 (3АО «НОВИЦ», Россия).

Для синтеза образца МС технический углерод П145 пропитывали 17\%-м водным раствором гептамолибдата аммония по влагоемкости $\left(\mathrm{V}_{\text {пор }}=1,25\right.$ мл/г), полученную пасту сушили на воздухе при $120^{\circ} \mathrm{C}$ до постоянной массы. Далее, проводили МА, полученного образа в водоохлаждаемой высокоэнергетической планетарной мельнице АГО-2, в инертной атмосфере (аргон), в качестве мелющих тел использовали шары диаметром 10 мм, соотношение масс образца и мелющих тел 1:40, ускорение мелющих тел 1000 м/с², время МА 30 мин. Ранее в работе [22] нами подробно изучалось влияние состава исходных компонентов и параметров механохимического синтеза на формирование карбида молибдена. В связи с этим были выбраны оптимальные параметры механической активации.

Таблица 1. Показатели технического углерода марки П145

Table 1. Characteristics of carbon black P145

\begin{tabular}{|c|c|c|c|}
\hline Размер частиц, нм & $\begin{array}{c}\text { Суммарный } \\
\text { объем пор, } \mathrm{cm}^{3} / \Gamma\end{array}$ & $\begin{array}{c}\text { Доля пор с размерами } \\
5-50 \mathrm{нм}, \mathrm{cm}^{3} / \Gamma\end{array}$ & $\begin{array}{c}\text { Удельная } \\
\text { поверхность, } \mathrm{M}^{2} / \Gamma\end{array}$ \\
\hline $18-25$ & 0,83 & 0,51 & 114 \\
\hline
\end{tabular}


В процессе МА возможно протекание следующих реакций:

$$
\begin{aligned}
& \left(\mathrm{NH}_{4}\right)_{6} \mathrm{Mo}_{7} \mathrm{O}_{24} \cdot 4 \mathrm{H}_{2} \mathrm{O}=7 \mathrm{MoO}_{3}+\mathrm{NH}_{3}+\mathrm{H}_{2} \mathrm{O}, \\
& \mathrm{MoO}_{3}+\mathrm{C}=\mathrm{MoO}_{2}+\mathrm{CO}, \\
& \mathrm{MoO}_{2}+5 \mathrm{C}=\mathrm{Mo}_{2} \mathrm{C}+4 \mathrm{CO} .
\end{aligned}
$$

Образец MCN с добавкой Ni в количестве 3 \% масс был приготовлен способом, аналогичным для образца МС. После стадии пропитки технического углерода П145 17\%-м водным раствором соли гептамолибдата аммония образец пропитывали 11\%-м водным раствором соли нитрата никеля, после каждой стадии пропитки следовала стадия сушки при $120{ }^{\circ} \mathrm{C}$ до постоянной массы. Механохимическую активацию полученного образа проводили в инертной среде на планетарной мельнице АГО-2, соотношение масс образца и мелющих тел 1:40, ускорение мелющих тел $1000 \mathrm{~m} / \mathrm{c}^{2}$, время МА 30 мин.

Механоактивированные образцы MC и MCN подвергали термической обработке (отжиг) в атмосфере аргона, нагрев проводили со скоростью $5{ }^{\circ} \mathrm{C} /$ мин до температуры $800{ }^{\circ} \mathrm{C}$ и выдерживали в течение 30 мин. Образцы после термообработки были обозначены MC-800 и MCN-800 соответственно.

Удельную поверхность по БЭТ механоактивированных образцов определяли экспрессметодом по $\mathrm{N}_{2}(77 \mathrm{~K})$ на приборе «СОРБТОМЕТР», Катакон.

Количества металлов в механоактивированных молибден-карбидных системах определяли методом атомно-эмиссионной спектрометрии с индуктивносвязанной плазмой (АЭС-ИСП) на приборе VARIAN 710-ES («Agilent Technologies»).

Фазовый состав синтезированных образцов изучали методом рентгенофазового анализа (РФА) на приборе D8 Advance («Bruker», Германия) в монохроматизированном СuК $\alpha$-излучении с длиной волны $1,5418 \AA$. Напряжение и ток накала составляли 40 кВ и 40 мА соответственно, шаг сканирования $2 \theta=0,02^{\circ}$, время накопления сигнала 2 с/точка, диапазон сканирования $10-80^{\circ} 2 \Theta$. С помощью программного комплекса EVA при использовании базы данных ICDD, PDF-2 (2006 г.) проводили фазовый анализ образцов.

Электронно-микроскопические исследования образцов проводили с использованием просвечивающего электронного микроскопа JEM-2100 «JEOL» (ускоряющее напряжение 200 кB, разрешение по кристаллической решетке 0,145 нм) с энергодисперсионным рентгеновским спектрометром INCA-250 «Oxford Instruments».

Оценку каталитических свойств высокодисперсных молибден-карбидных систем в процессе гидропереработки гудрона проводили в реакторе-автоклаве, принципиальная схема установки каталитических испытаний представлена на рис. 1. Физико-химические характеристики сырья даны в табл. 2. Содержание $\mathrm{C}, \mathrm{H}, \mathrm{N}, \mathrm{S}$ в гудроне и жидких продуктах определяли с помощью элементного анализатора Vario EL Cube.

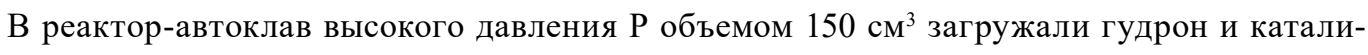
затор в массовом соотношении, равном 20:1 соответственно. Реактор с сырьем и катализатором продували водородом в течение 1,5 ч, затем кран К2 перекрывали и набирали давление 7 МПа. Далее, производили нагрев реактора со скоростью $5{ }^{\circ} \mathrm{C} /$ мин до температуры испытаний $470{ }^{\circ} \mathrm{C}$. Процесс гидропереработки гудрона проводили при постоянном перемешивании

$$
-567-
$$




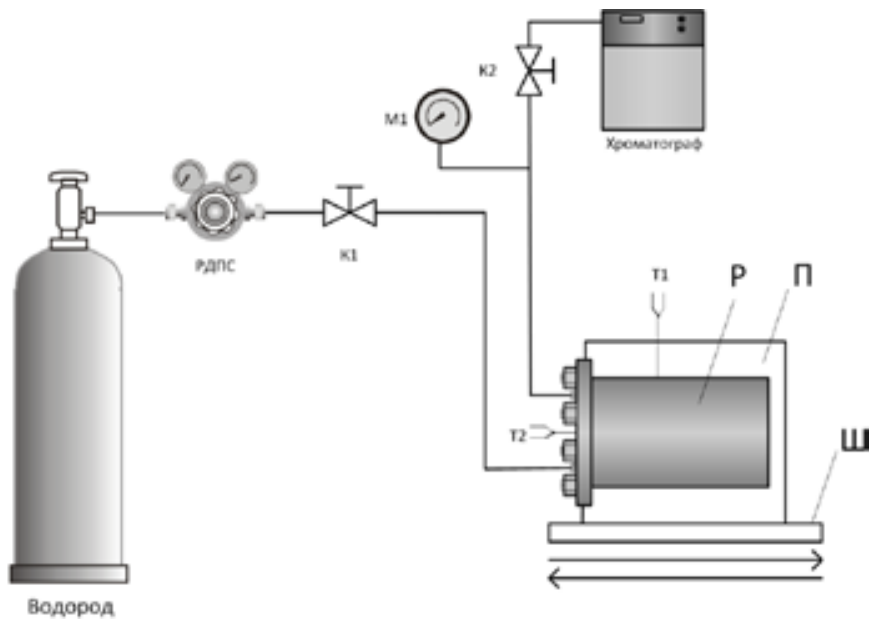

Рис. 1. Принципиальная схема лабораторной установки гидропереработки гудрона: $\mathbf{K}-$ кран запорный; РДПС - регулятор давления после себя; газа; М - манометр; П - печь; P - реактор; Т - термопара; Ш шейкер

Fig. 1. Scheme of laboratory setup hydroprocessing vacuum residue: $\mathbf{K}$ - stopcock; РДПС - pressure controller; $\mathbf{M}$ - manometer; $\boldsymbol{\Pi}$ - heater; $\mathbf{P}$ - reactor; $\mathbf{T}$ - thermocouple; $\mathbf{I}$ - shaker

\section{Таблица 2. Физико-химические показатели гудрона}

Table 2. Physicochemical characteristics of vacuum residue

\begin{tabular}{|c|c|}
\hline 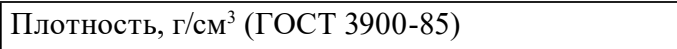 & 0,991 \\
\hline Элементный анализ, \% & \\
\hline $\mathrm{C}$ & 86,990 \\
\hline $\mathrm{H}$ & 11,060 \\
\hline $\mathrm{N}$ & 0,440 \\
\hline $\mathrm{S}$ & 1,280 \\
\hline $\mathrm{H} / \mathrm{C}$ & 0.127 \\
\hline Количество асфальтенов, \% (ASTM D6560) & 7,800 \\
\hline Коксуемость по Конрадсону, \% (ГОСТ 19932-99) & 21,000 \\
\hline
\end{tabular}

в течение 2 ч. Перемешивание сырья и катализатора в реакторе осуществляли с помощью шейкера Ш.

Состав газообразных продуктов превращения определяли с помощью газового хроматографа Хромос ГХ-1000. Углеводородные компоненты газовой фазы анализировали с использованием капиллярной колонки DB-1 $(60$ м $\times 0,25$ мм $\times 0,50$ мкм) «Agilent Technologies», газа-носителя аргона и пламенно-ионизационного детектора (ПИД). При анализе газообразных продуктов устанавливали следующую программу: начальная температура $40{ }^{\circ} \mathrm{C}$, выдержка 5 мин, нагрев со скоростью $4{ }^{\circ} \mathrm{C} /$ мин до $150{ }^{\circ} \mathrm{C}$, выдержка 15 мин.

Для определения количества кокса в твердых продуктах проводили экстракцию адсорбированных асфальтенов толуолом в аппарате Сокслета.

$$
-568-
$$


Выход жидких $\left(Y_{ж}\right)$ и твердых продуктов $\left(Y_{m}\right)$ превращения гудрона рассчитывали как отношение массы продукта к массе сырья:

$$
Y_{ж}, Y_{m}(\%)=\frac{\text { масса продукта (2) }}{\text { масса сырья (2) }} \times 100
$$

Выход газа $\left(Y_{2}\right)$ оценивали следующим образом:

$$
\mathrm{Y}_{\mathrm{r}}(\%)=100-\left(\mathrm{Y}_{\text {ж}}+\mathrm{Y}_{\mathrm{T}}\right) \text {. }
$$

\section{Результаты и обсуждения}

Содержание металлов и удельная поверхность для полученных образцов представлены в табл. 3. Железо образуется в результате намола материала мелющих тел и барабана.

Фазовый состав образцов после механической активации и последующего прокаливания в инертной атмосфере представлен на рис. 2 и 3 . Как видим на рис. 2 , для образца МС характерно наличие фаз, содержащих железо: $\mathrm{Fe}_{7} \mathrm{C}_{3}$ и $\mathrm{FeMoO}_{4}$. В прокаленном образце $\mathrm{MC}-800$ пик карбида молибдена на дифрактограмме при $40^{\circ} 2 \theta$ становится более четким и интенсивным, железо присутствует в виде $\mathrm{Fe}_{5} \mathrm{C}_{2}$.

Таблица 3. Характеристики массивного карбида молибдена и нанесенного катализатора состава $\mathrm{Mo}_{2} \mathrm{C} / \mathrm{C}$, полученные методом механической активации

Table 3. Characteristics of the MC- 800 and MCN-800, obtained by the method of mechanical activation

\begin{tabular}{|c|c|c|c|c|}
\hline \multirow{2}{*}{ Характеристика образца } & \multicolumn{3}{|c|}{ Содержание металлов, \% масс } & \multirow{2}{*}{ Удельная поверхность, $\mathrm{M}^{2} / \Gamma$} \\
\cline { 2 - 5 } & $\mathrm{Mo}$ & $\mathrm{Fe}$ & $\mathrm{Ni}$ & 94 \\
\hline MC-800 & 10,3 & 8,8 & - & 128 \\
MCN-800 & 10,3 & 9,0 & 2,9 & \\
\hline
\end{tabular}

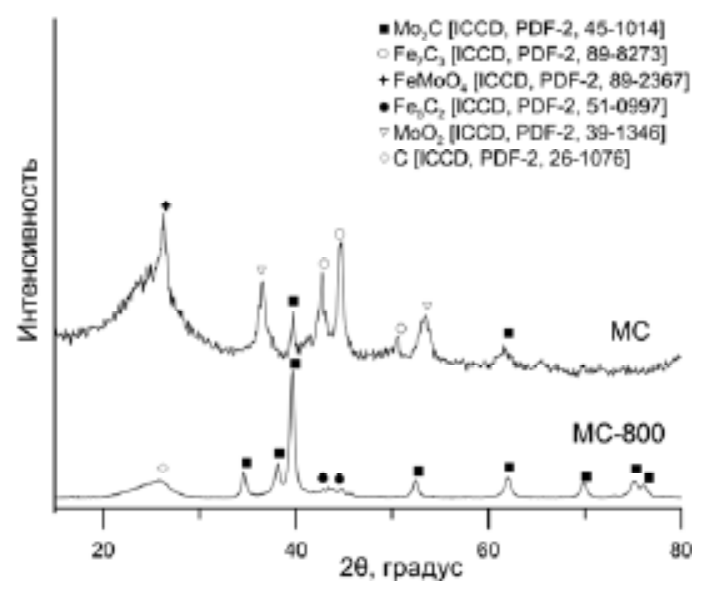

Рис. 2. Дифрактограммы образца МС после механической активации и последующей стадии отжига MC- 800

Fig. 2. Diffraction patterns of sample MC - after mechanical activation and the subsequent step of annealing MC- 800 


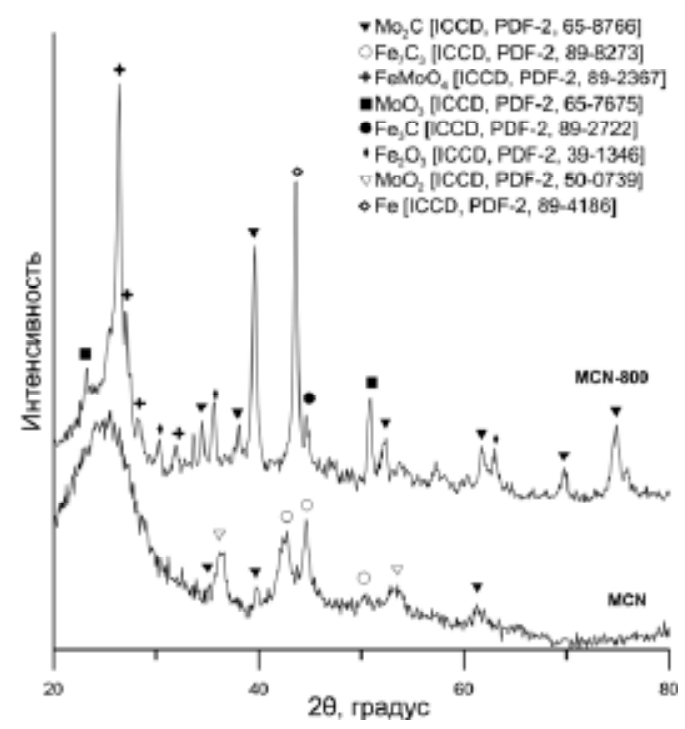

Рис. 3. Дифрактограммы образца MCN после механической активации и последующей стадии отжига $\mathrm{MCN}-800$

Fig. 3. Diffraction patterns of sample $\mathrm{MCN}$ - after mechanical activation and the subsequent step of annealing $\mathrm{MCN}-800$

На рис. 3 представлены дифрактограмма образца, прошедшего процедуру механической активации (MCN) и дифрактограмма мехактивированного образца после стадии отжига при $800^{\circ} \mathrm{C}$ в течение 30 мин (MCN-800). В непрокаленном мехактивированном образце MCN присутствуют фазы $\mathrm{Mo}_{2} \mathrm{C}, \mathrm{Fe}_{7} \mathrm{C}_{3}$ и $\mathrm{MoO}_{2}$, наличие последней свидетельствует о неполной карбидизации в процессе механической активации.

В прокаленном образце MCN-800 фиксируются четкие интенсивные пики, характерные для фазы $\mathrm{Mo}_{2} \mathrm{C}$, присутствуют фазы железосодержащих соединений, образующиеся вследствие намола материала мелющих тел и стенок барабана. Наличие никеля на дифрактограмме не зафиксировано из-за его рентгеноаморфности и высокой дисперсности.

С целью получения информации о морфологии и структуре образца МС-800 было проведено исследование методами просвечивающей электронной микроскопии высокого разрешения (ПЭМВР) и рентгеновского энергодисперсионного микроанализа (EDX).

Результаты, полученные из анализа снимков ПЭМВР и данных EDX для образца MC-800, представлены на рис. 4-6. Анализ данных подтверждает, что для образца характерно наличие конгломератов углеродных частиц произвольной формы размерами 0,1-2 $\mu$ м. На электронномикроскопических снимках высокого разрешения (рис. 5b) наблюдается кристаллическая решетка с параметрами: 0,261, 0,237, 0,228 нм, характерными для карбида молибдена (PDF 350787). Углеродная матрица в основном имеет аморфную структуру графеновых слоев. Однако вместе с этим наблюдаются упорядоченные углеродные образования, содержащие протяженные и параллельные друг другу графеновые слои. Среднее расстояние между этими слоями составляет 0,35 нм (рис. 4b).

В углеродной матрице содержатся наночастицы типа «ядро-оболочка», имеющие упорядоченные графеновые слои, сформированные вокруг частиц карбида молибдена. Рентгенов-

$$
-570-
$$


ские карты распределения железа, молибдена и кислорода в образце показывают равномерную пространственную локализацию элементов и углерода (рис. 6, рентгеновские карты железа и кислорода не показаны на рисунке).

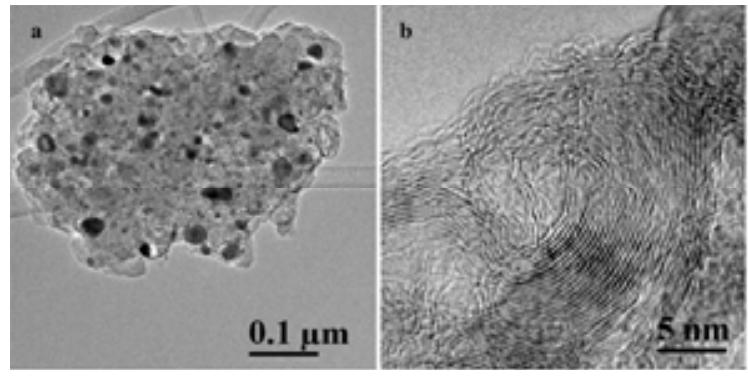

Рис. 4. Электронно-микроскопические изображения образца МC-800: a - наночастицы в углеродной матрице; $\mathrm{b}$ - структура графеновых слоев

Fig. 4. Electron microscopy images of sample MC-800. Particles in the carbon matrix - (a), structure of graphene layers (b)

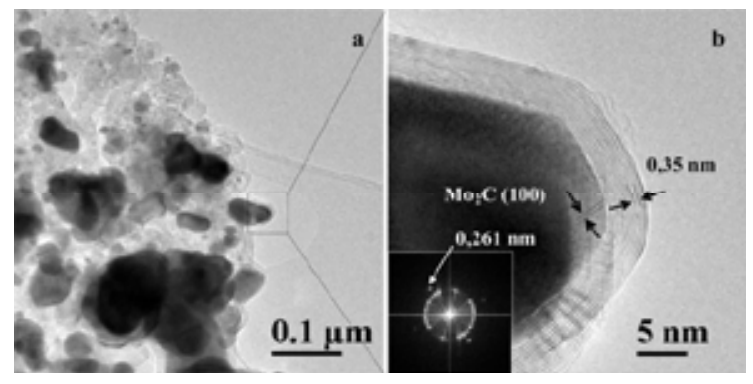

Рис. 5. Электронно-микроскопические изображения образца MC-800 (a), структуры «ядро-оболочка» и на вставке соответствующая ей электронограмма (b)

Fig. 5. Electron microscopy images of sample MC-800. "Coat-core" nanoparticles (a), corresponding electron transmission diffraction pattern in the inset (b)

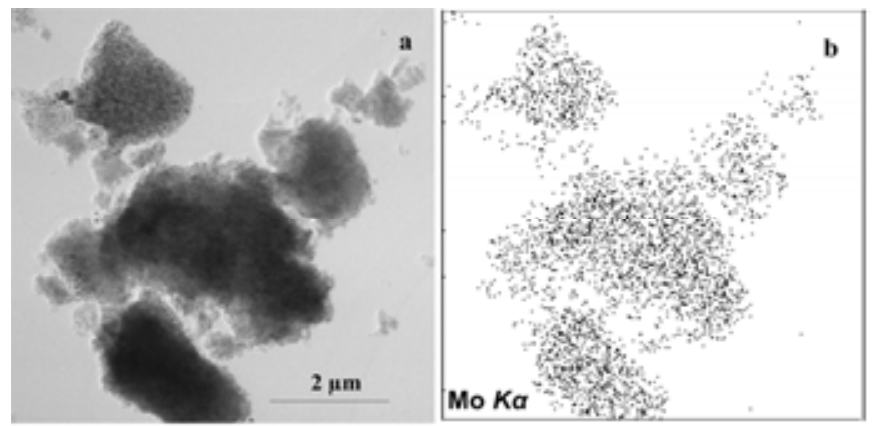

Рис. 6. Электронно-микроскопическое изображение конгломератов частиц образца МC-800 (a), соответствующая данной области рентгеновская карта распределения молибдена (b)

Fig. 6. Electron microscopy images of sample MC-800 (a), corresponding X-ray map showing the spatial distribution of molybdenum in the sample (b) 
Таблица 4. Состав продуктов гидропереработки гудрона

Table 4. Composition of hydroprocessing products of vacuum residue

\begin{tabular}{|l|c|c|c|}
\hline \multicolumn{1}{|c|}{ Показатель } & \multicolumn{2}{|c|}{ Катализаторы } \\
\cline { 2 - 4 } & Без катализатора & MC-800 & MCN-800 \\
\hline Плотность, г/см ${ }^{3}$ & 0,865 & 0,860 & 0,953 \\
Содержание S в жидких продуктах, \% & 1,147 & 1,021 & 38,3 \\
Состав продуктов, \% мас. & & & 49,4 \\
Газы С- C $_{4}$ & 33,3 & 41,7 & 12,3 \\
Жидкие продукты & 28,7 & 39 & 10 \\
Твердые продукты & 38 & 19,3 & 15 \\
в том числе кокс & 30,3 & & \\
\hline
\end{tabular}

Каталитическое действие молибден-карбидных систем MC-800 и MCN-800 было оценено в процессе гидропереработки гудрона при температуре $470{ }^{\circ} \mathrm{C}$, начальном давлении водорода 7 МПа, в течение 120 мин. Был проведен сравнительный анализ результатов каталитических испытаний образцов MC-800, MCN-800 с результатом, полученным в ходе проведения процесса без катализатора в аналогичных условиях, данные представлены в табл. 4.

Стоит отметить, что в случае использования высокодисперсных карбидсодержащих катализаторов выход твердых продуктов, в том числе кокса, значительно снижается наряду с увеличением выход жидких продуктов.

Применение никель-молибденового карбидсодержащего образца MCN-800 позволяет достичь наибольшего выхода жидких продуктов - 49.4 \%, обеспечивает снижение выхода кокса в три раза, что составляет $10 \%$, уменьшение содержание серы в жидких продуктах в 1,5 раза по сравнению с данными полученными в процессе без катализатора.

\section{Выводы}

В работе предложен способ получения высокодисперсных молибден-карбидных каталитических систем методом механической активации в инертной среде. Исследованы состав и морфология молибден-карбидных систем. Методом ПЭМВР установлено, что для молибденкарбидных систем характерно наличие частиц типа «ядро-оболочка», имеющих упорядоченные графеновые слои, сформированные вокруг частиц $\mathrm{Mo}_{2} \mathrm{C}$, среднее расстояние между которыми составляет 0,35 нм. Проведена оценка каталитического поведения молибден-карбидных систем в slurry-процессе гидропереработки гудрона и установлено, что в присутствии молибденкарбидного катализатора наблюдается снижение выхода кокса более чем в три раза по сравнению с содержанием кокса, полученного при тех же температурно-временных параметрах процесса без катализатора.

Работа выполнена в рамках государственного задания ИППУ СО РАН в соответствии с Программой фундаментальных научных исследований государственных академий наук на 2013-2020 годы по направлению V.46, проект № V.46.4.4 (номер госрегистрации в системе ЕГИСУ НИОКТР АААА-A17-117021450098-2). 


\section{Список литературы}

1. Guangzhou J., Jianhua Z., Xiuju F., Guida S., Junbin G. Effect of Ni promoter on dibenzothiophene hydrodesulfurization performance of molybdenum carbide catalyst. Chinese Journal of Catalysis 2006. Vol. 27(10), P. 899-903.

2. Guli-Lopez R., Nieto E., Botas J.A., Fierro J.L.G. On the genesis of molybdenum carbide phases during reduction-carburization reactions. Journal of Solid State Chemistry 2012. Vol. 190, P. 285-295.

3. Wang J.X., Ji S.F., Yang J., Zhu Q., Li S. Mo2C and Mo2C/A12O3 catalysts for NO direct decomposition. Catalysis Communications 2005. Vol. 6(6), P. 389-393.

4. Delannoy L., Giraudon J.-M., Granger P., Leclercq L., Leclercq G. Group VI transition metal carbides as alternatives in the hydrodechlorination of chlorofluorocarbons. Catalysis Today 2000. Vol. 59(3-4), P. 231-240.

5. Sayag C., Benkhaled M., Suppan S., Trawczynski J., Djega Mariadassou G. Comparative kinetic study of the hydrodenitrogenation of indole over activated carbon black composites (CBC) supported molybdenum carbides. Applied Catalysis A: General 2004. Vol. 275(1-2), P. 15-24.

6. Frauwallner M.L., López-Linares F., Lara-Romero J., Scott C.E., Ali V., Hernández E., PereiraAlmao P. Toluene hydrogenation at low temperature using a molybdenum carbide catalyst. Applied Catalysis A: General 2011. Vol. 394(1-2), P. 62-70.

7. Espinoza-Monjardín, Cruz-Reyes J., Del Valle-Granados M., Flores-Aquino E., AvalosBorja M., Fuentes-Moyado S. Synthesis, characterization and catalytic activity in the hydrogenation of cyclohexene with molybdenum carbide. Catalysis Letters 2008. Vol. 120(1-2), P. 137-142.

8. Puello-Polo E., Brito J.L. Effect of the activation process on thiophene hydrodesulfurization activity of activated carbon-supported bimetallic carbides. Catalysis Today 2010. Vol. 149(3-4), P. 316-320.

9. Szymanska-Kolasa A., Lewandowski M., Sayag C., Brodzki D., Djega-Mariadassou G. Comparison between tungsten carbide and molybdenum carbide for the hydrodenitrogenation of carbazole. Catalysis Today 2007. Vol. 119(1-4), P. 35-38.

10. Han J., Duan J., Chen P., Lou H., Zheng X., Hong H. Nanostructured molybdenum carbides supported on carbon nanotubes as efficient catalysts for one-step hydrodeoxygenation and isomerization of vegetable oils. Green Chemistry 2011. Vol. 13, P. 2561-2568.

11. Rocha A.S., da Silva V.L.T., Leitao A.A., Herbst M.H., Faro Jr.A.C. Low temperature low pressure benzene hydrogenation on Y zeolite-supported carbided molybdenum. Catalysis Today 2004. Vol. 98(1-2), P. 281-288.

12. Pritchard M.L., McCauley R.L., Gallaher B.N., Thomson W.J. The effects of sulfur and oxygen on the catalytic activity of molybdenum carbide during dry methane reforming. Applied Catalysis A: General 2004. Vol. 275(1-2), P. 213-220.

13. Tominaga H., Nagai M. Theoretical study of methane reforming on molybdenum carbide. Applied Catalysis A: General 2007. Vol. 328(1), P. 35-42.

14. Dai-Viet N.V., Adesina A.A. Fischer-Tropsch synthesis over alumina-supported molybdenum carbide catalyst. Catalysis A: General 2011. Vol. 399(1-2), P. 221-232.

15. Barthos R., Solymosi F. Aromatization of n-heptane on Mo2C-containing catalysts. Journal of Catalysis 2005. Vol. 235(1), P. 60-68.

$$
-573-
$$


16. Lamic A.-F., Shin C.-H., Djega-Mariadassou G., Potvin C. Characterization of Mo2C-WO2 composite catalysts for bifunctional isomerization: A new pulse method to quantify acid sites. Applied Catalysis A: General 2006. Vol. 302(1), P. 5-13.

17. Ge C., Jiang P., Cui W., Pu Z. H., Xing Z., Asiri A.M., Obaid A.Y., Sun X., Tian J. Shapecontrollable synthesis of Mo2C nanostructures as hydrogen evolution reaction electrocatalysts with high activity. Electrochimica Acta 2014. Vol. 134, P. 182-186.

18. Weigert E.C., South J., Rykov S.A., Chen J.G. Multifunctional composites containing molybdenum carbides as potential electrocatalysts. Catalysis Today 2005. Vol. 99(3-4), P. 285-290.

19. Xiang M., Li D., Zou J., Li W., Sun Y., She X. XPS study of potassium-promoted molybdenum carbides for mixed alcohols synthesis via CO hydrogenation. Journal of Natural Gas Chemistry 2010. Vol. 19(2), P. 151-155.

20. Ardakani S.J., Liu X., Smith K.J. Hydrogenation and ring opening of naphthalene on bulk and supported Mo2C catalysts. Applied Catalysis A: General 2007. Vol. 324, P. 9-19.

21. Pritchard M.L., McCauley R.L., Gallaher B.N., Thomson W.J. The effects of sulfur and oxygen on the catalytic activity of molybdenum carbide during dry methane reforming. Applied Catalysis A: General 2004. Vol. 275(1-8), P. 213-220.

22. Baklanova O.N., Vasilevich A.V., Lavrenov A.V., Drozdov V.A., Muromtsev I.V., Arbuzov A.B., Trenikhin M.V., Sigaeva S.S., Temerev V.L., Gorbunova O.V., Likholobov V.A., Nizovskii A.I., Kalinkin A.V. Molybdenum carbide synthesized by mechanical activation an inert medium. Journal of Alloys and Compounds 2017. Vol. 698, P. 1018-1027. 